\title{
Biological Investigations of the Whole Plant of Argemone mexicana (L.)
}

\author{
Farjana Rahman Chaity, Mohammad A. Rashid and \\ Mohammad Sharifur Rahman \\ Department of Pharmaceutical Chemistry, Faculty of Pharmacy, University of Dhaka, \\ Dhaka-1000, Bangladesh
}

Received: April 18, 2021; Accepted: May 22, 2021; Published (web): June 20, 2021)

Argemone mexicana L. (Family: Papaveraceae), locally known as Sheyal kata, is indigenous to South America and naturalized to tropical and sub-tropical regions including United States, India, Bangladesh, etc. The plant is familiar as "Sheyal Kata" in Bangla and "Prickly poppy" in English. It is a prickly herb having the height of $30-120 \mathrm{~cm}$. Leaves are like thistle, flowers are yellow, fruits are capsule and seeds are brownish black. ${ }^{1}$

The plant is known as both toxic and medicinal herb. It was reported to have nematocidal, anthelmintic, wound recovering, antidiabetic, antiHIV and other activities. Numerous alkaloids, steroids, flavonoids, amino acids have been isolated from this herb. ${ }^{2}$ Ethnopharmacologically, various parts of this herb were reported to be useful in the treatment of inflammations, malarial fever, ulcers, skin diseases, cough, asthma, leprosy, conjunctivitis etc. ${ }^{3}$ Previously, leaf and root of this plant were reported to exhibit anti-inflammatory and analgesic properties. $^{4,5}$ The present study was designed to investigate the toxicity, membrane stabilizing, thrombolytic and free radical scavenging potentials along with total phenolic contents of different solvent extractives of whole plant of A. mexicana.

The whole plant of A. mexicana L. was collected from Shusong Durgapur, Netrokona district in March, 2013. A voucher specimen for this collection

*Correspondence to: Mohammad Sharifur Rahman

Email: msr@du.ac.bd

Dhaka Univ. J. Pharma. Sci. 20(1): 135-138, 2021 (June) DOI: https://doi.org/10.3329/dujps.v20i1.54041
(Accession number: DACB - 38387) has been deposited at Bangladesh National Herbarium, Mirpur Road-1, Dhaka-1216 for future references. The fresh plant materials were cut into small pieces and shed dried for several days. The dried plant materials were ground into coarse powder by using a grinding machine and preserved in an airtight container for further uses. About $800 \mathrm{~g}$ of powdered sample was soaked in methanol. The whole mixture was then filtered by white cotton material, followed by filtration with Whatman filter paper no. 1. The crude extract thus obtained was concentrated by evaporating methanol with a rotary evaporator (Heidolph, Germany) at low pressure and $37^{\circ} \mathrm{C}$ temperature to yield a gummy material $(13.0 \mathrm{~g})$ which is labelled as the methanol extract of $A$. mexicana (MEAM). The methanol extract was then subjected for solvent-solvent partitioning ${ }^{6}$ to get petroleum ether (PEAM), carbon tetrachloride (CTCAM) and chloroform (CAM) soluble materials, with the yield values of 7.25, 3.64 and $1.11 \mathrm{~g}$, respectively.

Brine shrimp (Artemia salina) lethality is a bench top bioassay to assess the preliminary toxicity and bioactivity of phytoconstituents. ${ }^{7}$ Previously, a small scale trial was performed with this herb ${ }^{8}$ but this is the first time, when the methanol extract of whole plant of $A$. mexicana and its different Kupchan partitionates were subjected to this assay. The lethal concentration $\left(\mathrm{LC}_{50}\right)$ was obtained from the graph of number of shrimps died versus the concentration of plant extract after 24 hours of treatment (Table-1). Vincristine sulfate (VS) was used as the positive 
control for this assay. The order of lethality was $\mathrm{PEAM}>\mathrm{CAM}>\mathrm{CTCAM}>\mathrm{MEAM}$.

Table 1. $\mathrm{LC}_{50}$ Values of the test samples of A. mexicana in $A$. salina lethality assay.

\begin{tabular}{lccc}
\hline Samples & Regression line & $\mathrm{R}^{2}$ & $\begin{array}{c}\mathrm{LC}_{50} \\
(\mu \mathrm{g} / \mathrm{ml})\end{array}$ \\
\hline MEAM & $\mathrm{y}=34.226 \mathrm{x}+21.306$ & 0.909 & 6.89 \\
PEAM & $\mathrm{y}=12.885 \mathrm{x}+71.927$ & 0.913 & 0.02 \\
CTCAM & $\mathrm{y}=28.588 \mathrm{x}+42.339$ & 0.787 & 1.85 \\
CAM & $\mathrm{y}=22.549 \mathrm{x}+51.873$ & 0.905 & 0.83 \\
VS & $\mathrm{y}=30.79 \mathrm{x}+60.65$ & 0.973 & 0.45 \\
\hline
\end{tabular}

MEAM $=\mathrm{MeOH}$ extract of $A$. Mexican $;$ PEAM= Petroleum ether soluble fraction of $\mathrm{MeOH}$ extract of A. Mexicana; CTCAM = Carbon tetrachloride soluble fraction of $\mathrm{MeOH}$ extract of $A$. Mexicana: $\mathrm{CAM}=$ Chloroform soluble fraction of $\mathrm{MeOH}$ extract of A. Mexicana, $\mathrm{VS}=$ Vincristine sulfate.

Membrane stabilizing assay pioneered by Shinde et al. $(1999)^{8}$ was used to evaluate the capacity of the plant extractives to inhibit RBC hemolysis. RBC membrane stabilization mimics the prevention of the breakdown of lysozyme membrane inhibiting the lysozyme mediated inflammation. ${ }^{9}$ The results showed (Figure 1a) that the MEAM (48.31\%) and CTCAM $(21.06 \%)$ were noticeably potent to prevent hemolysis induced by hypotonic solution.

Thrombolytic assay established by Prasad et al. 2007 was used here to explore the thrombolytic potentials of the extractives by using human blood. ${ }^{10}$ The maximum thrombolytic effect was shown (Figure 1b) by MEAM (22.39\%). Other fractions showed exhibited very weak thrombolytic activity.
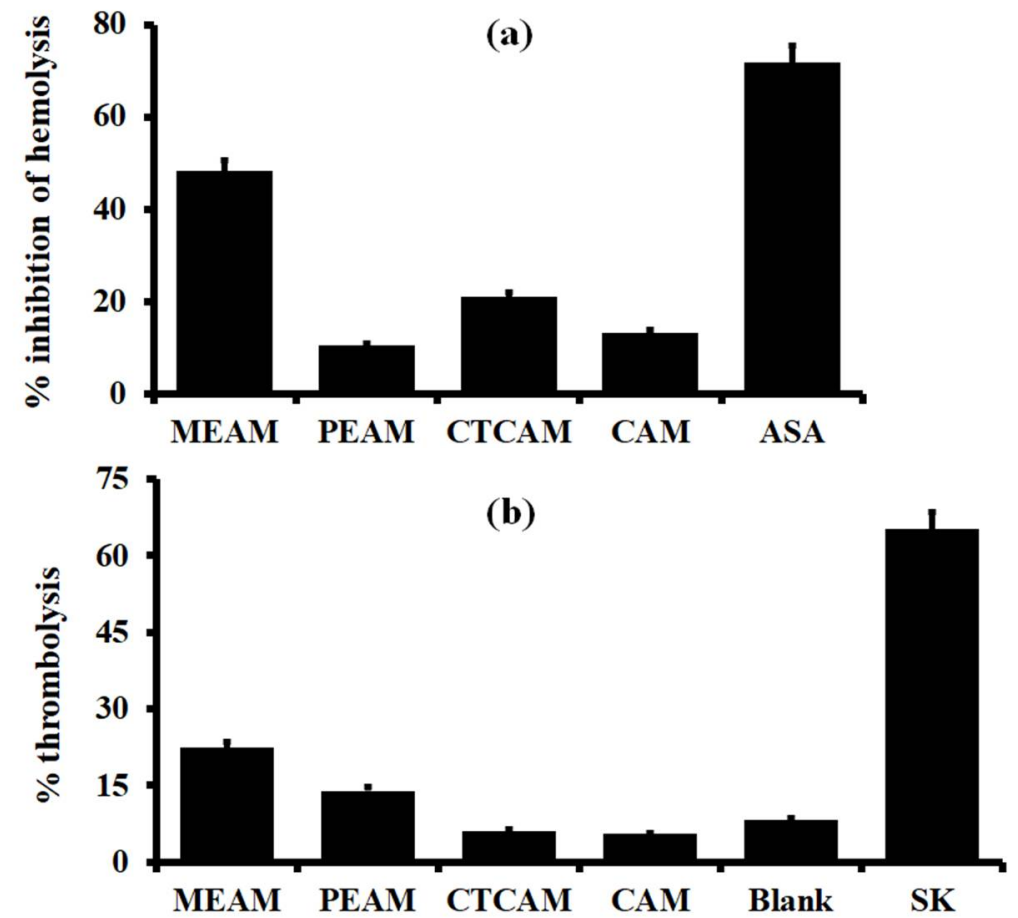

Figure 1a. \% inhibition of hemolysis of RBC prompted by hypotonic solution and (b) \% thrombolysis of human blood by different extractives of A. mexicana. ASA= Acetylsalicylic acid (standard); Blank (water); SK=Streptokinase.

Phenolic content in the plant extractives is a sign of antioxidant potentials, which can be measured by using Folin-Ciocalteu reagent. ${ }^{11}$ By using gallic acid as standard, the highest phenolic content was found in MEAM (305.61 mg of GAE/g of extractives). The order of phenolic contents in the extractives was
MEAM > CTCAM > CAM > PEAM (Figure 2a).

DPPH (2,2-diphenyl-1-picrylhydrazyl) free radical scavenging assay was used to explore the antioxidant potentials of the extractives. ${ }^{12}$ In this study, the chloroform soluble partition of methanol 
extract of whole plant of A. mexicana revealed the maximum free radical scavenging activity with an $\mathrm{IC}_{50}$ value of $10.4 \mu \mathrm{g} / \mathrm{ml}$. The order of free radical inhibitory potential was CAM > CTCAM > MEAM

$>$ PEAM (Figure 2b).
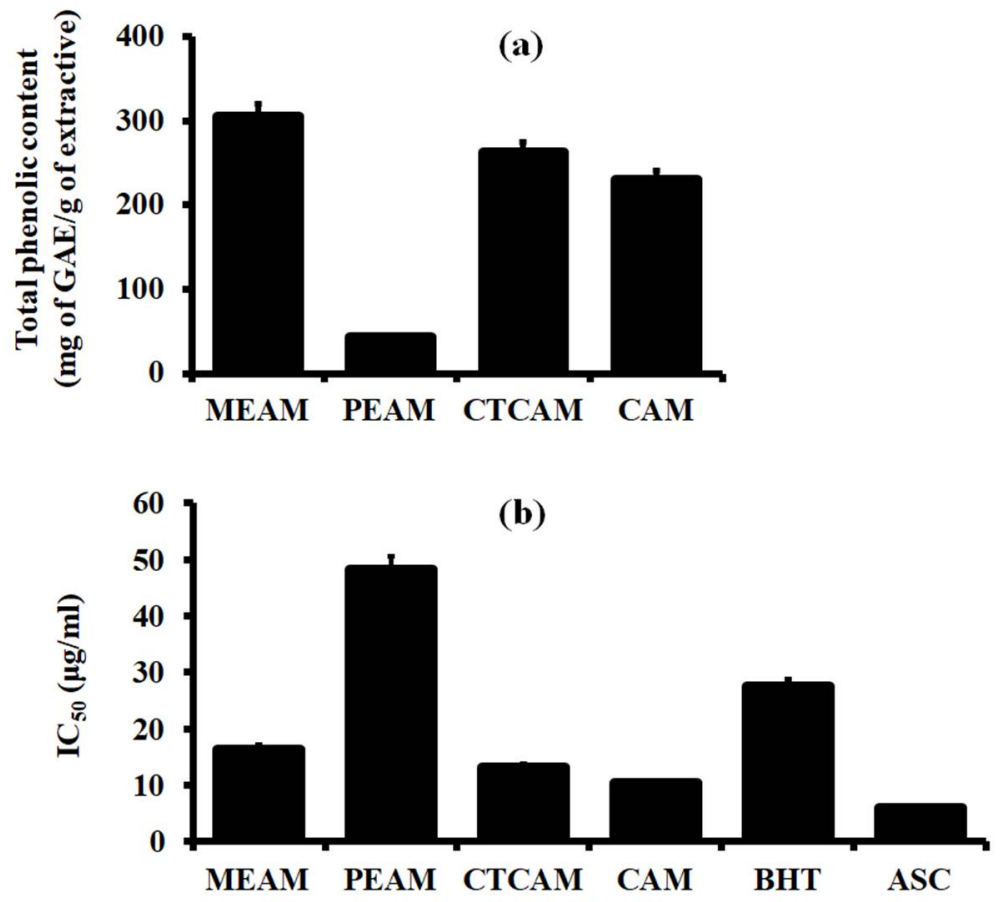

Figure 2b. Total phenolic content and (b) $\mathrm{IC}_{50}$ values of DPPH free radical scavenging of different extractives of A. mexicana. BHT= Butylated hydroxytoluene (standard); ASC=Ascorbic acid (standard).

The methanol extract of the whole plant of $A$. Mexicana and its fractions were also subjected to antimicrobial screening for the first time with a concentration of $400 \mu \mathrm{g} / \mathrm{disc}$ by using agar well disc diffusion method. ${ }^{12}$ Several gram positive (Sarcina lutea, Bacillus cereus, B. subtilis, B. megaterium and Staphylococcus aureus) and gram negative bacteria (Pseudomonus aeroginosa, Escherichia coli, Shigella boydii, S. dysenteriae, Salmonella paratyphi, S. typhi, Vibrio mimicus and $V$. parahemolyticus) were used in this purpose. Only the PEAM and CTCAM exhibited antimicrobial activity with the zone of inhibition ranging from 9 to $10 \mathrm{~mm}$ against the tested microorganisms (data not shown).

The results of our current study, justifies the ethnopharmacological and medicinal uses of $A$. Mexicana to some extent. The results of the bioactivities demonstrated that the extractives can be used for preparing effective herbal formulations.
However, fraction based further phytochemical analysis might explore the bioactive principles responsible for these pharmacological actions.

\section{REFERENCES}

1. Brahmachari, G., Gorai, D. and Roy, R. 2013. Argemone mexicana: chemical and pharmacological aspects. Rev. Bras. Farmacogn. 23, 559-575.

2. Nancy, A. and Praveena, A. 2017. Argemone mexicana: a boon to medicinal and pharmacological approaches in current scenario. Cardiovasc. Hematol. Agents Med. Chem. 15, 7890.

3. Rajvaidhya, S., Nagori, B., Singh, G., Dubey, B., Desai, P. and Jain, S. 2012. A review on Argemone mexicana Linn.-an Indian medicinal plant. Int. J. Pharm. Sci. Res. 3, 2494-2501.

4. Ibrahim, H., Umar, M.A., Bello, B.A., Aliyu, A. and Ahmad, A. 2016. Analgesic and anti-inflammatory studies on the roots Argemone mexicana Linn (Family: Papaveraceae). J. Pharm. Biol. Sci. 11, 92-95.

5. Sourabie, T., Ouedraogo, N., Sawadogo, W., Nikiema, J., Guissou, I. and Nacoulma, O. 2012. Biological evaluation of anti-inflammatory and analgesic activities of Argemone 
mexicana Linn.(Papaveraceae) aqueous leaf extract. Int. J. Pharm. Sci. Res. 3, 451-458.

6. VanWagenen, B.C., Larsen, R., Cardellina, J.H., Randazzo, D., Lidert, Z.C. and Swithenbank, C. 1993. Ulosantoin, a potent insecticide from the sponge Ulosa ruetzleri. J. Org. Chem. 58, 335-337.

7. Meyer, B.N., Ferrigni, N.R., Putnam, J.E., Jacobsen, L.B., Nichols, D.E. and McLaughlin, J.L. 1982. Brine shrimp: a convenient general bioassay for active plant constituents. Planta Med. 45, 31-34.

8. Nahar, A., Habib, A., Awal, M., Rahman, A.S., Mondal, M.G. and Alam, M.S. 2014. Studies on antifungal activity and brine shrimp toxicity Argemone mexicana. KYAMC J. 4, 402-405.

9. Shinde, U., Phadke, A., Nair, A., Mungantiwar, A., Dikshit, V. and Saraf, M. 1999. Membrane stabilizing activity- a possible mechanism of action for the anti-inflammatory activity of Cedrus deodara wood oil. Fitoterapia. 70, 251257.
10. Prasad, S., Kashyap, R.S., Deopujari, J.Y., Purohit, H.J., Taori, G.M. and Daginawala, H.F. 2006. Development of an in vitro model to study clot lysis activity of thrombolytic drugs. Thromb. J. 4, 14.

11. Ahmed, F. and Rahman, M.S. 2016. Preliminary assessment of free radical scavenging, thrombolytic and membrane stabilizing capabilities of organic fractions of Callistemon citrinus (Curtis.) skeels leaves. BMC Complement. Altern. Med. 16, 247.

12. Jahan, F.N., Rahman, M.S., Hossain, M. and Rashid, M.A. 2008. Antimicrobial activity and toxicity of Quisqualis indica. Orient. Pharm. Exp. Med. 8, 53-58. 